\title{
Notícias / News
}

\section{ACESSO À INFORMAÇÃO NA ÁREA DE SAÚDE AMBIENTAL}

Com o objetivo de facilitar 0 acesso às informa. çőes documentárias relativas, principalmente, aos documentos "não convencionais" que têm distribuição restrita ou são de difícil acesso, como por exemplo, relatórios técnicos, teses, documentos de trabalhos, etc., foi criada a Rede Panamericana de Información y Documentación en Ingenieria Sanitária y Ciencias Ambientales - REPIDISCA.

A REPIDISCA está integrada por um Centro Coordenador - CEPIS (Lima, Perú) e por Centros Nacionais Cooperantes (CNC), localizados em diversos países da América Latina, e que são responsáveis pela coordenação das atividades da Rede, a nível nacional. E financiada em parte com fundos internacionais da Organização Panamericana da Saúde, do Centro Internacional de Investigação para - Desenvolvimento do Canadá e pelo Centro Internacional para Abastecimento Público de Água, da Holanda.

A REPIDISCA oferece informações relacionadas com serviços de água, saneamento e problemas de engenharia sanitária e ambiental existentes nos Centros Nacionais Cooperantes (CNC).

A Faculdade de Saúde Pública da Universidade de São Paulo participará, através de seu Serviço de Biblioteca e Documentação, como Centro Cooperante da REPIDISCA e passará a enviar informaçðes especializadas nas áreas acima mencionadas e a fornecer cópias dos documentos aos interessados.

A REPIDISCA produz dois tipos de alertas informativos: O REPINDEX e o TABCONT/CEPIS. O primeiro é uma bibliografia trimestral com resumos dos documentos que integram a base de dados, a cada três meses, e o segundo traz a lista do conteúdo de 55 periódicos selecionados, com índices de assuntos. Essas publicaçōes podem ser adquiridas através de subscrição anual.

Além disso, a REPIDISCA oferece serviço de pesquisa bibliográfica com o objetivo de localizar informaçōes, quer seja em bibliografias, indices acumulados, material de um determinado país ou dos países que colaboram com a Rede. A Base de
Dados da Rede oferece ainda a possibilidade de serem produzidos: Catálogo Coletivo, Catálogo de Instituições Especializadas, Catálogo de Especialistas, Catálogo de Pesquisas em Andamento, Tesauro "MISCA" e Disseminação Seletiva da Informação.

Dessa forma, docentes, pesquisadores, técnicos, planejadores e profissionais que atuam no campo de engenharia sanitária, ambiental e saúde ocupacional, poderão ter acesso à informação atualizada, o que facilitará a tomada de decisóes e o desenvolvimento de novos conhecimentos e técnicas no seu campo de ação.

\section{Endereços: REPIDISCA}

- Repartição Sanitária Pan-Americana Caixa Postal 04-2229 - 70000 - Brasilia, DF

- Centros Nacionais Colaborantes no Brasil:

- Banco Nacional da Habitação (BNH) Av. Chile, $230 \cdot 17^{\circ}$ andar Rio de Janeiro, RJ

- Companhia de Saneamento do Paraná (SANEPAR)

Rua Engenheiros Rebouças, 1376 Curitiba, PR

- Companhia de Tecnologia de Saneamento Ambiental (CETESB)

Av. Prof. Frederico Hermann Jr., 345 São Paulo, SP

- Companhia Municipal de Limpeza Urbana (COMLURB)

Rua Major Ávila, 358 - 39 andar - 20511

Rio de Janeiro, RJ

- Fundação Estadual de Engenharia do Meio Ambiente (FEEMA)

Rua Fonseca Telles, $121 \cdot 15$ ? andar

Caixa Postal 23011 20000

Rio de Janeiro, RJ

- Secretaria Especial do Meio Ambiente (SEMA)

Esplanada dos Ministérios, Bloco 23 Brasilia, DF

\section{S I C T E X}

\section{SISTEMA DE INFORMAÇÃO CIENTIFICA E TECNOLOGICA DO EXTERIOR}

O Ministério das Relações Exteriores, através de sua Divisão de Ciência e Tecnologia - DCTEC, é responsável pelo Sistema de Informação Científica e Tecnológica do Exterior (SICTEX).
O SICTEX tem por objetivo assegurar a captação, no exterior, de informaçôes científicas e tecnológicas (ICTs), de interesse para o Brasil, e promover sua difusão entre os órgãos integrantes do Sistema Na- 
cional de Desenvolvimento Científico e Tecnológico e outras entidades brasileiras, públicas ou privadas, envolvidas na ciência e tecnologia.

As informaçðes científicas e tecnológicas veicula. das pelo Sistema são prioritariamente:

a) informaçoes ou documentos de circulação restrita ou de difícil acesso tais como teses, publicaçðes governamentais, relatórios técnicos, relatórios de pesquisas;

b) informaçōes ou resumos de pesquisas em andamento;

c) informações ou descrição de projetos de pesquisa;

d) relatórios de síntese;

e) informações sobre eventos ou trabalhos resul. tantes dos mesmos;

f) informaçðes diversas sobre entidades ou sobre pesquisadores;

g) dados estatísticos e legislação relativa às diversas áreas científicas;

h) descrição de marcas e patentes, etc.

As formas de apresentação das informaçð̃es coletadas no exterior podem ser:

- textos elaborados pelo SICTEX por meio de publicação periódica "Informativo SICTEX"

- originais impressos

- microformas

\section{O SICTEX tem a seguinte estrutura:}

1) Uma Unidade Central, que funciona na Divisão de Ciência e Tecnologia - DCTEC do Ministério das Relaçð̃es Exteriores, com o apoio do Instituto Brasileiro de Informação em Ciência e Tecnologia (IBICT).

2) Nove setores de Ciência e Tecnologia - SECTECs, que operam junto às embaixadas do Brasil em Berna, Bonn, Camberra, Londres, Nova Delhi, Ottawa, Paris, Tóquio e Washington. Encontramse em fase de instalação cinco novos SECTECs nas embaixadas de Moscou, Pequim, Roma, México e Buenos Aires.

3) Unidades Informacionais - Uls, que correspondem a centros setoriais de documentação responsáveis, no Brasil, pelo encaminhamento dos pedidos de ICTs através do SICTEX e pelo armazenamento e disseminação dessas informações entre os usuários brasileiros. A cada área do conhecimento corresponde uma UI, selecionada pelo IBICT, que tem sua sede em determinado órgão ou instituição brasileira.
As entidades e demais interessados nas informações do SICTEX devem formular seus pedidos à Unidade Informacional, correspondente à sua área de interesse.

As informaçס̄es fornecidas aos usuários são armazenadas na UI que, eventualmente, a transmitirá a outras entidades ou outros interessados.

Os serviços do SICTEX são oferecidos gratuitamente. No entanto, se as informaçðes solicitadas forem de alto custo, os serviços prestados pelo sistema serão cobrados.

Principais Unidades Informacionais, de interesse para a Saúde Pública:

- Biotecnologia - Agropecuária/EMBRAPA -

CENARGEN - Setor de Informação/C.P. 102372

Brasília - 70.849

Saúde/FIOCRUZ - Biblioteca Central / C.P. 926

Rio de Janeiro - 21.040

- Ciência e Tecnologia de Alimentos / ITAL - SIT

C.P. 139 / Campinas, SP - 13.100

- Desenvolvimento urbano; Habitação, Saneamento/Min. Interior - Centro de Documentação Espl. dos Ministérios - Térreo/Brasília - 70.054

- Meio Ambiente/SEMA - Centro de Documentação/Av.W/3 Norte-Q.510-Ed.Cidade de Cabo Frio, 7750/Brasília - 70.750 .

- Metereologia e Climatologia/INEMET - Biblioteca/Pça. XV de Novembro, 22 ? andar Centro/Rio de Janeiro - 20.000

- Politica Cientifica e Tecnológica/CNPq-CPO Av. W/3 Norte - Q. 507 - B1. B / Brasilia - 70.740.

- Recursos Naturais Hidricos / DNAEE - DCRH Centro de Documentação / SRTS - Q. 701 Conj. E - Bl. 3 - Ed. Palácio do Rádio - Subsolo Brasilia - 70.030 .

- Recursos Naturais Vegetais e Faunisticos UFRGS - CICA / R. Sarmento Leite, S.N. Porto Alegre, RS - 90.000

- Saude e Nutrição / MIN. SAÚDE - Centro de Documentação / Espl. dos Ministérios - B1. 2 Térreo / Brasilia - 70.058.

- Trópico Semi-Arido / UFPb - CISA - Biblioteca Setorial do Campus II / R. Aprígio Velloso, 882 Bodocongó / Campina Grande, PB - 58.100.

- Trópico Úmido (inclui Botânica e Zoologia) MPEG - Centro de Documentação da Amazônia C.P. 399 - Belém, PA - 66.000 . 